\title{
BACKWARD ASSOCIATION IN PAIRED-ASSOCIATE LEARNING $^{1}$
}

\author{
CHIZUKO IZAWA ${ }^{2}$
}

University of Tokyo

\begin{abstract}
The process of formation of backward association in PAL was investigated: the 50 experimental $S$ s were tested upon reaching one of the 5 stages of the a-b task. Upon reaching a criterion the first and second members of a pair were reversed and the b-a task followed to a criterion of one perfect trial. The 10 control $S \mathrm{~s}$ participated in the b-a task only. Common nouns with equal meaningfulness were used for both members of a pair. The results were: (a) Backward associations were formed at all stages of forward learning, (b) The more forward learning, the more backward associations were acquired, (c) A superiority of backward association was discovered early in learning, but backward association was inferior at the other stages of PAL, (d) Among the experimental conditions, the speed of b-a learning was the same at any given stage of $b$-a learning before the terminal point of learning, (e) Positive transfer occurred from the $a-b$ task to the b-a task, (f) The more the a-b learning, the greater the transfer, and (g) A given directionality of PAL might be a function of the relative weakness of backward association. A free recall test supported this interpretation.
\end{abstract}

Events occur in sequences, and human experiences and actions have their directions. Thus, temporal and directional relationships are of crucial importance in many psychological events. It is well known, for example, that in classical conditioning the temporal and directional relationship is almost irreversible. That is, backward conditioning is said to be impossible.

${ }^{1}$ This article is based upon part of a thesis submitted by the author to the University of Tokyo in 1960 in partial fulfillment of the requirements for the degree of Bachelor of Arts. Grateful acknowledgement is made by the author to Prof. M. Sagara and Mr. H. Saiga for their assistance as advisors in the conduct of the present study. While the experiment was conducted in the years 1959-60, this article includes later developments by various writers on the same subject. The writing of this English manuscript was supported in part by Grant NSF-G24264 of the National Science Foundation of the United States Government and in part by a grant-in-aid from Stanford University.

2 Now at Stanford University, Stanford, Calif., U.S.A.
The problem of backward association has been investigated ever since the very beginning of the experimental work in verbal learning by Ebbinghaus in 1885. However, the results and the interpretations of these investigations tend to be contradictory. For example, writers such as Wohlgemuth (1912), Guthrie (1933) and Hermans (1936) reported that backward recall was as strong as forward recall, and Stoddard (1929) even reported the superiority of backward associations. Most often, however, backward associations have been reported to be distinctly weaker than forward associations, as seen in the work of Hermans (1936), Kuraishi (1937), Trowbridge (1938), Umemoto (1951), Morikawa (1955, 1959), Feldman and Underwood (1957), Jantz and Underwood (1958), etc. While McGeoch (1936), Wilson (1949), and Raskin and Cook (1937) presented data which showed the existence of backward associations, considerable skepticism concerning their existence was expressed by Garrett and Hartman (1926), Bunch and Lund (1932), Dorcus (1932), Nagel (1912) 
and Cason (1924, 1926).

Theoretical explanations of backward association have been attempted by such investigators as Lepley (1934), Guthrie (1935), Gibson (1940), Peters (1935), Robinson (1932), Meyer (1939), Kuraishi (1937), Umemoto (1951), and Morikawa $(1955,1959)$. However, no one of these hypotheses can by itself satisfactorily explain the complex phenomena of backward association in paired-associate learning (PAL).

Asch and Ebenholtz in a recent study (1962), attacked the problem of backward association in PAL and proposed the principle of associative symmetry using the concept of availability. Horowitz, Brown and Weissbluth (1964) supported this. Asch and Ebenholtz (1962) asserted that association is a fundamentally cognitive process and concluded that "When an association is formed between two distinct items $a$ and $b$, it is established simultaneously and with equal strength between $b$ and $a . "$ For them, the relative weakness of backward associations over forward associations is an artifact of the experimental operations, i.e. the anticipation method.

In Exp. I of Asch and Ebenholtz study, 8 pairs of nonsense syllables were learned by the method of anticipation. One group of $S \mathrm{~s}$ learned the list to a criterion of a minimum of four out of eight correct on a single trial. The other group learned to a criterion of one perfect performance on a single trial. Upon reaching their respective criteria $S$ s were asked to recall in any order as many pairs and single items as possible. The results showed that $S$ s recalled significantly more $b$ items than a items for both groups. From this, they concluded that "the customary technique of testing for backward association is structured so as to favor the measure of forward association," and that " tests of forward and backward association have been derived from the recall of terms differing in availability."

Further in Exp. $V$ of the same study,
Asch and Ebenholtz first presented $S$ with 16 items for free recall. In order to make all items "available" $S_{\mathrm{s}}$ had several trials of free recall training. Then, these 16 terms were arranged into 8 pairs which were presented to $S$ s by a modified anticipation method. In the final test, each stimulus and response item was presented individually and $S$ s were instructed to supply its partner. The $S$ s in the control condition participated in a standard PAL and a final aided recall test without the initial free recall training. In the final test, the experimental group produced about an equal amount of backward association and forward association, whereas the control group produced a significantly greater number of forward associations. They concluded that in the experimental group, the availability of the members of a pair was equal and thus the difference between backward and forward association of learning disappeared, and that in the control group, the standard anticipation method produced a higher availability of the response members than of the stimulus members of a pair. By comparing these two experiments, they further concluded that the level of backward association obtained in aided recall (where $S$ is instructed to respond to one of the two members of a given pair) was essentially the same as the level of recall of the same items as measured by free recall.

Exp. V of Asch and Ebenholtz, however, suffers from certain difficulties. First, the two groups (experimental and control) may not necessarily be comparable. It is commonly assumed that PAL is the end product of three types of learning, namely (a) stimulus differentiation, (b) response learning, and (c) association learning. The experimental $S$ might be helped to learn (a) and (b) although he did not know which items would be stimulus and response members of the pairs. The first part of this experiment might facilitate subsequent PAL in a complex way. The $S$ s of the experimental condition and the 
control condition were engaged in different types of learning. Secondly, the frequent free recall test during the first item learning of the experimental condition served to increase each item's differentiation and especially availability in Asch and Ebenholtz's sense. Availability, for them, is defined in terms of free recall, or its equivalent aided recall. That is, for Asch and Ebenholtz, the free recall items are available items.

Horowitz, Brown, and Weissbluth (1964) proposed that the probability of an item's recall be used as a measure of its availability, and attempted to show associative symmetry by using certain associative structures. For Exp. I, they constructed 6 pairs, each contributing to a structure shown by the following diagram:

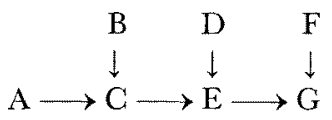

An arrow in the diagram leads from a stimulus to a response member of a pair. That is, $\mathrm{A} \rightarrow \mathrm{C}$ indicates that $\mathrm{A}$ serves as stimulus for $\mathrm{C}$. These 6 pairs were presented in 4 independent orders by a modified anticipation method until the $S$ reached a criterion of one perfect trial (Cond. 1) or three perfect trials (Cond. 2). $S$ pronounced the stimulus word when it appeared. After he mastered the PA task, he was instructed to supply two different associations for each item presented to him from the above 7 items. Response hierarchies were determined by the relative frequency of occurrence. Following this associative structure, Horowitz et al. noted that "First, the task required C, E, and $\mathrm{G}$ to become equally available since $S$ had to utter them about equally often. Second, the only available stimuli were those in the associations $\mathrm{C} \rightarrow \mathrm{E}$, and $\mathrm{E} \rightarrow \mathrm{G}$." Therefore, they expected backward association to occur readily under these conditions. This expectation was confirmed by the data of Exp. I where the combined mean frequency of occurrence of both Set $\mathrm{N}$ (nonsense syllables) and Set W (English words) of the aided free recall items was as follows: $\mathrm{C}$ elicited $\mathrm{E} 41 \%$ of the time, and $\mathrm{E}$ elicited $\mathrm{C} 39 \%$ of the time; $\mathrm{E}$ elicited $\mathrm{G} 42 \%$, and $\mathrm{G}$ elicited $\mathrm{E} 40 \%$. This seemed to be good evidence for associative symmetry. However, the results of Exp. II cast doubt on this interpretation. The learning task and procedures of their second experiment were exactly like those of Cond. 1 in Exp. I excepting one important change. The associative link between $\mathrm{C}$ and $\mathrm{E}$ was deleted. The resulting structure is shown in the following diagram:<smiles>[2H][14CH2][14CH2][14CH3]</smiles>

Thus, Ss learned only 5 pairs in this experiment. Horowitz et al. stated that "Items $\mathrm{C}, \mathrm{E}$, and $\mathrm{G}$ continued to be the only available items" and also that "GE was the only backward association of Exp. II whose response was available." Their data showed EG GE symmetry, since E elicited $\mathrm{G} 42 \%$, and $\mathrm{G}$ elicited $\mathrm{E} 44 \%$. The striking part of the data of Exp. II, however, is that E elicited C $24 \%$ of the time. Remember that in Exp. II, E and C were not linked. If one follows their reasoning, $\mathrm{C}$ should not be available to $\mathrm{E}$ at all, and C's occurrence to $\mathrm{E}$ should be negligible just as $\mathrm{E}$ to $\mathrm{A}(2 \%)$ and $\mathrm{E}$ to $\mathrm{B}$ $(6 \%)$ are negligible, since $\mathrm{A}, \mathrm{B}$, and $\mathrm{C}$ were detached from $\mathrm{E}$ in their associative structure. Since $\mathrm{E}$ elicited $\mathrm{C}$ with probability of .24 without linkage to $\mathrm{G}$ (Exp. II) the EC probability (with linkage) of .39 (Exp. I) is based to a considerable degree on factors other than associative symmetry. Thus, while symmetry appears to be implied by the equality of the associative strengths of EC (.39) and CE (.41), this equality is seen to arise in part from an artifact. There were only two pairs whose members were equally available according to their definition: i.e. pairs $\mathrm{CE}$ (EC) and EG (GE). Absence of data precludes a similar analysis of the EG 
(GE) relationships. However, it is conceivable that GE would have had a similarly high probability without linkage.

It would be instructive to try to find some sources of contradiction concerning backward association appearing in the literature. In the present article, therefore, the author posed the following questions to help to understand an old and at the same time new problem in backward association in paired-associate learning: (a) How is backward association in PAL formed? (b) Is the amount of backward association as great as forward association (associative symmetry)? (c) How does previous $a-b$ learning transfer to the later $\mathrm{b}$-a learning, where $\mathrm{a}$ and $\mathrm{b}$ represent the first and second members respectively of a given pair of the first task?

The concept of availability has been discussed in terms of free recall (Asch and Ebenholtz, 1962) or aided free recall (Asch and Ebenholtz, 1962; and Horowitz et al., 1964). These writers assume that associative symmetry can be explained by this concept of availability. To test this contention, the $S$ s of the present study were instructed to recall freely just what they had learned when they finished the PAL tasks. If the amount of free recall is the index of availability, then it has to be highly correlated with the association formed during PAL.

According to Asch and Ebenholtz, the anticipation method produces differential availability of items of the pairs. Thus, for them the stronger forward association is an artifact. If so, what will happen if the stimulus and response items are reversed in the middle of the a-b task, and $S$ continues to learn b-a pairs to the criterion? The present study helps to provide answers to these questions.

\section{EXPERIMENT}

\section{Materials}

In order to minimize item learning (stimulus differentiation and response learning) in PAL, and thus in order to investigate the effect of association in PAL from the data, common words (Japanese) were used. Twenty-four two-syllable nouns were selected from the norms by Umemoto et al. (1955), for $L$ ist $L_{1}$ and for List $\mathrm{L}_{2}$, making 12 pairs each. The meaningfulness of each noun was above 160, and the average degree of meaningfulness of stimulus and response items was equated for both lists. That is, the learnability of each item of a pair was made equal. Each of the Japanese words was selected so that its meaning was concrete, clear and distinct. The frequency of occurrence of the same KANA-letter was minimized within the same list. In particular, among the stimulus members or the response members of the same list, no KANA-letter appeared more than once with a few exceptions. The two lists (Lists $\mathrm{L}_{1}$ and $\mathrm{L}_{2}$ ) were constructed on the basis of the same rules. List $\mathrm{L}_{1}{ }^{\prime}$ and $\mathrm{List} \mathrm{L}_{2}{ }^{\prime}$ were also constructed: they were identical to List $\mathrm{L}_{1}$ and List $\mathrm{L}_{2}$ respectively except that their stimulus and response members were reversed. Hence, Lists $L_{1}$ and $L_{2}$ were $a-b$ lists, while Lists $\mathrm{L}_{1}^{\prime}$ and $\mathrm{L}_{2}^{\prime}$ ' were b-a lists.

In this study, " $a$ " and " $b$ " denote respectively the first and the second member of a given pair of List $\mathrm{L}_{1}$ or List $\mathrm{L}_{2}$, which was given to the $S$ as his first task. Consequently, Lists $\mathrm{L}_{\mathbf{1}}$ and $\mathrm{L}_{2}$ were said to be $\mathrm{a}-\mathrm{b}$ lists, since " $\mathrm{a}$ " and " $b$ " were defined as the first and second members of the pairs. This above definition justifies naming List $L_{1}{ }^{\prime}$ and List $L_{2}{ }^{\prime} b$ ba lists. This follows from the fact that Lists $\mathrm{L}_{1}{ }^{\prime}$ and $\mathrm{L}_{2}{ }^{\prime}$ were identical to Lists $L_{1}$ and $L_{2}$ except that the first and second members of the pairs were reversed.

The term " $a-b$ learning" is defined operationally as learning $\mathrm{a}-\mathrm{b}$ lists. That is, when the experimenter gave the $S$ a-b pairs ( $L$ ist $\mathrm{L}_{1}$ or $\mathrm{L}_{2}$ ) and the $S$ responded with " b" terms by a modified anticipation method in the present study, then the $S$ was said to be engaged in a-b learning. Likewise, the term "b-a learning" is defined operationally as learning b-a pairs (List $\mathrm{L}_{1}{ }^{\prime}$ or $\mathrm{L}_{2}{ }^{\prime}$ ). In b-a learning, the $S$ 's task was to respond "a" terms by a modified anticipation method.

The pairs of Lists $L_{1}$ and $L_{2}$ were as follows : 


\section{LIST $L_{1}$}

\begin{tabular}{|c|c|c|c|}
\hline & & & \\
\hline L & (ASHI) & 一占ゆ & (FUYU) \\
\hline はみ & (NAMI) & 一をち & (MACHI) \\
\hline かま & (KAMA) & 一とり & (TORI) \\
\hline 叔 & (YANE) & ーらた & (UTA) \\
\hline$\pm \infty$ & (SAME) & 一注す & (HASU) \\
\hline すな & (SUNA) & 一ひと & (HITO) \\
\hline kつ & (KUTSU) & 一よる & (YORU) \\
\hline$-z$ & (KOE) & ータせ & (MISE) \\
\hline & (TAKE) & 一えさ & $(\mathrm{ESA})$ \\
\hline & $(\mathrm{IMO})$ & 一つき & (TSUKI) \\
\hline & (KIKU) & 一しか & (SHIKA) \\
\hline & (MURA) & 一肪や & (OYA) \\
\hline & & ST L & \\
\hline & (YANE) & 一あゆ & $(\mathrm{AYU})$ \\
\hline & $(\mathrm{HAE})$ & 一刮加 & (OKA) \\
\hline & (FUTA) & $-5 \mathrm{~L}$ & (USHI) \\
\hline & (ISU) & 一なみ & (NAMI) \\
\hline & (KINU) & 一えさ & (ESA) \\
\hline & (KAME) & 一ちり & (CHIRI) \\
\hline & (MATO) & -nや & (HEYA) \\
\hline & (SHIRO) & 一こけ & (KOKE) \\
\hline & (TSUNA) & 一に & (NIWA) \\
\hline & (SORA) & $-た$ & (TAKI) \\
\hline & (MICHI) & $-<\varnothing$ & (KUMO) \\
\hline & (SARU) & & (NUMA) \\
\hline
\end{tabular}

Experimental Conditions

There were 6 conditions. They were differentiated in terms of the $S$ 's first task (a-b learning) as indicated in Table 1. The criterion of the second task (b-a learning) was one perfect performance with 12 pairs on a single trial. This was the same for all conditions.

Condition A was a control. The $S_{\mathrm{S}}$ in this condition had no a-b task prior to the b-a task,

\section{TABLE 1}

Experimental conditions

\begin{tabular}{ccc}
\hline Task & $\begin{array}{c}\text { Criteria of a-b } \\
\text { learning task } \\
\text { Minimum correct } \\
\text { on a single trial }\end{array}$ & $\begin{array}{c}\text { Criteria of b-a } \\
\text { learning task }\end{array}$ \\
\hline A & (no a-b task) & 1 perf. \\
B & 3 & 1 perf. \\
C & 6 & 1 perf. \\
D & 9 & 1 perf. \\
E & 1 perf. & 1 perf. \\
F & 3 perf. & 1 perf.
\end{tabular}

while $\mathrm{B}, \mathrm{C}, \mathrm{D}, \mathrm{E}$, and $\mathrm{F}$ were experimental conditions with the a-b task assigned first. The first trial of b-a tasks served as the test trial (TEST) of the backward association of the first task (a-b learning).

Ten $S$ s were randomly assigned to one of the 6 conditions depending on the order in which they showed up. Half of them learned Lists $\mathrm{L}_{1}-\mathrm{L}_{1}{ }^{\prime}$ only, and the other half, Lists $\mathrm{L}_{2}-\mathrm{L}_{2}{ }^{\prime}$ only. Lists $L_{1}$ and $L_{2}$ were for their first task and Lists $\mathrm{L}_{1}{ }^{\prime}$ and $\mathrm{L}_{2}{ }^{\prime}$ were for their second task respectively.

\section{Experimental Procedures}

Each $S$ was presented with two practice pairs first and was required to learn them ( $a-b$ learning task only). After a very brief rest, he was assigned to one of the 6 conditions and given one of the two lists for the first task, a-b learning. Condition A, the control, did not have this task. The $S$ s were first simply instructed to participate in the $a-b$ learning task with a modified anticipation method, and were not informed about the later tasks at all.

Each stimulus-response pair in the PA task was stamped on a $15 \times 20 \mathrm{~cm}$ index card. The letters used were Japanese HIRA-GANA letters. These cards appeared behind a $14.7 \times 38 \mathrm{~cm}$ cardboard screen with an aperture of $2 \times 9 \mathrm{~cm}$. $E$ exposed the stimulus item alone in the right side of the aperture for $3 \mathrm{sec}$, and then moved the index card so as to expose the response item alone for $3 \mathrm{sec}$ on the left side of the aperture. There was no delay between stimulus and response presentations, but the delay between pairs was $1 \mathrm{sec}$, during which time a white index card was shown in the aperture. The intertrial interval lasted approximately $10 \mathrm{sec}$. After all the items had been presented once, $S$ was instructed to anticipate the response during a 3 sec stimulus presentation. The pairs were presented in random order on each trial, and the procedure was repeated to an assigned criterion. With one minor change in size and time intervals, identical experimental apparatus and procedures were used in the author's experiments at Stanford University: Izawa (1962), Izawa et al. (1962), Horowitz and Izawa (1963), etc.

Upon reaching a given criterion in his a-b task, the $S$ was told that a rest time came since 
he had learned what was required. After 3 min rest, during which time $S$ and $E$ engaged in light conversation, $S$ was instructed to resume the PA task with stimulus and response items reversed. Thus, List $L_{1}{ }^{\prime}$ or $L_{2}{ }^{\prime}$ was given to him instead of previous List $L_{1}$ or $L_{2}$. He was informed about $b$-a learning at the beginning of this second task for the first time. The experimental procedures of $\mathrm{b}-\mathrm{a}$ learning were exactly the same as previous $a-b$ learning except that the $S$ started responding on the first trial. His second task was completed when he reached 12 correct (one perfect performance) on a single trial, and he was told that his PA task was completed. The $S$ s in Condition A learned only the b-a task with procedures identical to those of the $a-b$ task for the experimental Condition $\mathrm{E}$.

A brief rest with light conversation followed $S$ 's PA task. Then, each $S$ was handed a sheet of paper $(22 \times 28 \mathrm{~cm})$, and instructed to write down as many pairs or items as possible in any order (free recall test). He was given as much time as needed for this test.

Immediately after the free recall test, each $S$ was asked whether he had used any mnemonic devices to help to learn the given pairs, and $E$ recorded $S$ 's remarks.

Subjects

Sixty $S \mathrm{~s}, 10$ in each condition, participated in this experiment. These $S_{s}$ were freshman boys and girls attending public high schools in Tokushima, Japan. None of them had had previous experience in verbal learning experiments.

\section{Results}

On no measure were there significant differences between List $L_{1}\left(L_{1}{ }^{\prime}\right)$ and List $\mathrm{L}_{2}\left(\mathrm{~L}_{2}^{\prime}\right)$. Consequently, the results from List $\mathrm{L}_{1}\left(\mathrm{~L}_{1}{ }^{\prime}\right)$ and $\mathrm{L}_{2}\left(\mathrm{~L}_{2}^{\prime}\right)$ were combined. This lack of difference can be taken as evidence for generality of the results which was not restricted by the specific characteristics of the materials employed in this study.

\section{Acquisition}

Table 2 presents the mean number of trials needed to reach a given criterion on
Table 2

Mean number of trials to reach criterion in each condition for each task

\begin{tabular}{lccc}
\hline Condition & $\begin{array}{c}\mathrm{a}-\mathrm{b} \text { learning } \\
\text { (first task) }\end{array}$ & $\begin{array}{c}\mathrm{b}-\mathrm{a} \text { learning } \\
\text { (second task) }\end{array}$ & Total \\
\hline A $(0 / 12)$ & 0 & 11.0 & 11.0 \\
B $(3 / 12)$ & 3.5 & 7.5 & 11.0 \\
C $(6 / 12)$ & 5.4 & 6.9 & 12.3 \\
D $(9 / 12)$ & 6.6 & 5.9 & 12.5 \\
E (1 perf.) & 8.9 & 4.3 & 13.2 \\
F (3 perf.) & 12.7 & 3.0 & 15.7
\end{tabular}

each learning task by the $S_{\mathrm{s}}$ in each condition.

To provide evidence that there were no differences between the two lists, 3 types of analysis of variance were done. First, the $a-b$ learning task alone was analyzed over 5 conditions (since Condition A had no $a-b$ task) with double classification with 5 scores per cell. The results revealed significant differences between the conditions, $F(4,40)=18.37, p<.001$. No difference was found between lists, $F(1,40)$ $=.14$. The interaction between condition and list was not significant either, $F(4$, $40)=1.47$. Second, the b-a task alone was analyzed over 6 conditions including Condition A. Again, great differences were revealed between conditions, $F(5,48)$ $=14.17, p<.001$, with no difference between lists, $F(1,48)=.11$. No significant interaction between condition and list was found, $F(5,48)=.84$. Third, an analysis of variance was done for overall trials with two-way classification (condition and task) with 10 scores in each cell. As might well be expected, again the differences between conditions were significant, $F(5,108)$ $=2.73 \mathrm{I}, p<.05$. There was no significant difference between tasks, $F(1,108)=.337$; but the interaction was exceedingly high, $F(5,108)=45.777, p<.001$ : that is, if $S$ required a relatively high number of trials in $a-b$ learning, he required a relatively low number of trials in b-a learning, and vice versa. 
TABLE 3

Mean strengths of forward and backward associations when criteria were reached

\begin{tabular}{lccc}
\hline Condition & $\begin{array}{c}\text { Forward } \\
\text { association }\end{array}$ & $\begin{array}{c}\text { Backward } \\
\text { association }\end{array}$ & $\begin{array}{c}\text { Difference } \\
(\mathrm{B}-\mathrm{F})\end{array}$ \\
\hline B $(3 / 12)$ & 4.3 & 5.5 & +1.2 \\
C $(6 / 12)$ & 6.9 & 6.0 & -.9 \\
D $(9 / 12)$ & 10.2 & 7.9 & -2.3 \\
E $(1$ perf. $)$ & 12.0 & 9.4 & -2.6 \\
F $(3$ perf. $)$ & 12.0 & 11.0 & -1.0
\end{tabular}

\section{Backward association}

In order to compare the relative strength of forward and backward association, it is very important to measure just how much forward association has been formed when the $S$ s of each condition have reached a given criterion. This was entered in the first column of Table 3 . The first trial of the b-a learning task of each experimental condition served as the test (TEST) of backward association formed during the previous a-b learning task. This score was entered in the second column of the same table.

The analysis of variance revealed a highly significant difference between forward and backward association, $F(1,90)=11.802$, $p<.001$. That is, when the modified anticipation method was employed, the amount of backward association was significantly different from that of the forward association at a given stage of learning. The differences between conditions were, of course, highly significant, $F(4,90)=59.587$, $p<.001$. The interaction turned out to be significant also, $F(4,90)=4.331, p<.01$.

One of the most important results deals with the difference between forward and backward association formed during learning. The figures in the third column of Table 3 result from subtracting forward association scores from backward association scores. In Conditions C, D, E, and F, backward association was significantly less than forward association. These conditions alone seemed to support Asch and Ebenholtz, who asserted that the anticipa- tion or the modified anticipation method produced differential availability of items so that backward association was weaker.

However, such an explanation was not appropriate for the result of Condition B. In this condition, backward association was significantly stronger than forward association. This discovery was quite surprising. The strength of backward association relative to that of forward association is shown in Fig. 1, where forward association is given an arbitrary score of 100 . This presentation permits one to visualize how much forward learning was accompanied by backward learning, depending on the stage of PA learning. Superiority of backward association over forward association in Condition B is impressive. Backward association was weaker for the other conditions and decreased as forward learning proceeded, and it was weakest when from two-thirds to all of the pairs were learned (Conditions D and E). When the list was overlearned, however, backward association was improved.

$b$-a learning

The learning curves were drawn for the

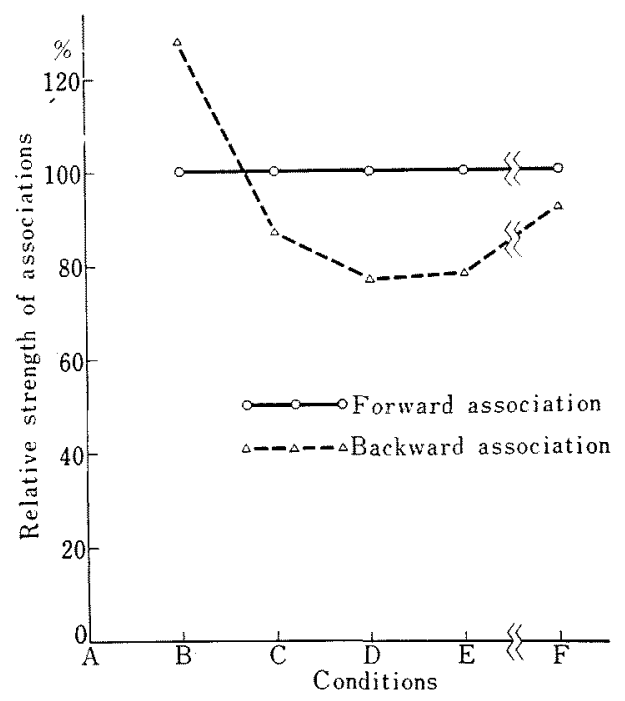

FIG. 1. Relative strength of forward and backward association (Forward association $=100$ ). 
second task (b-a learning) for all conditions. If backward association in PAL is a completely different process from forward association, then b-a learning must be new learning. If so, the learning curves of all experimental groups (Conditions B, C, D, $\mathrm{E}$, and $\mathrm{F}$ ) would not differ from that of the control group (Condition A). If not, there would be a significant difference between the control curve and each of the 5 experimental curves; and the difference between the two groups should be interpreted as due to the effect of previous $a-b$ learning on later b-a learning. The above statement follows from the fact that backward (b-a) association acquired during previous $a-b$ learning was the same association that was learned as forward (b-a) association during later b-a learning. Fig. 2 should provide information relating to the above questions.

An analysis of variance was carried out on the data for trials 1 through 4 using the double classification with 10 scores per cell. The obvious reason for the analysis for trials 1 through 4 was that Condition $F$ required only 4 trials to reach the experimental criterion. There were highly significant differences between trials:
$F(3,216)=28.367, p<.001$. The interaction between trial and condition was not significant. The analysis of variance also revealed highly significant differences between conditions: $F(5,216)=59.587$, $p<.001$. In addition, 5 l-tests were performed on the difference between the control and each of the 5 experimental conditions. The $t$ 's were 3.909 (Condition $A$ vs. Condition B), 5.380 (A vs. C), 7.182 (A vs. D), 10.912(A vs. E), and 13.188(A vs. F). All $t$-tests were significant at the level of .001 . Therefore, the difference between the control curve and each of the experimental curves is statistically significant. It is important to note that the more the $\mathrm{a}-\mathrm{b}$ learning, the greater the $t$-value.

${ }^{3}$ (Fig. 2, Condition A) Since the $S$ s of Condition $\mathrm{A}$ had no prior $\mathrm{a}-\mathrm{b}$ task, and since they were shown the entire 12 pairs of b-a task first, before they started responding, their scores on trial 1 were comparable to trial 2 scores for the other conditions. Shifting their learning curve one trial to the right results in greater transfer from forward to backward association. Therefore, the amount of this transfer might be greater than is indicated in Fig. 2. However, leaving this curve as it is does not change the interpretation of the results. Thus, the trials can be interpreted as response trials.

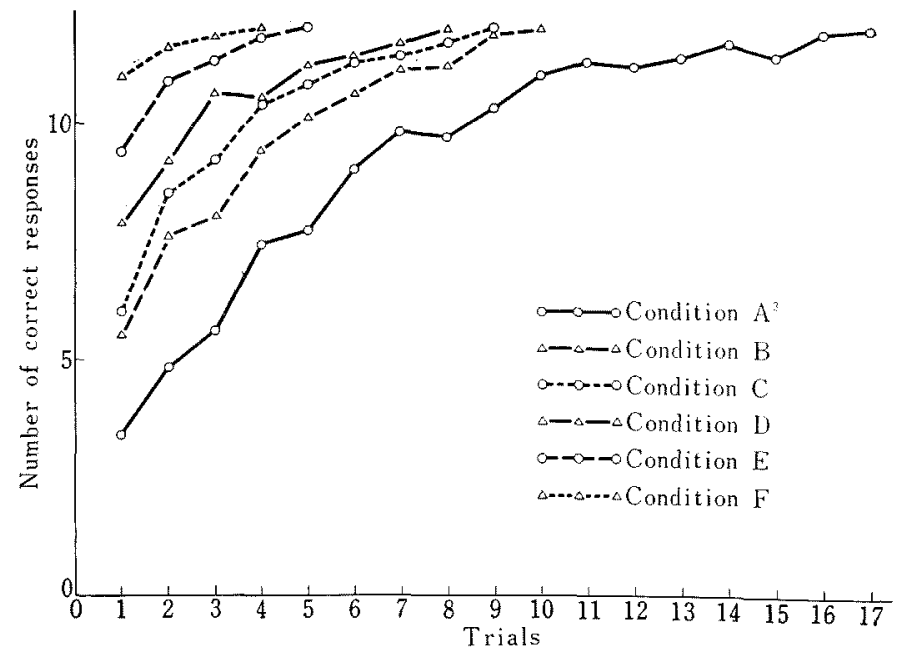

Fig. 2. Learning curve of b-a task. 
Next, backward learning curves were drawn as shown in Fig. 3. Those curves were derived from the learning curves in Fig. 2. The major operation for this was to fix the terminal point of each learning curve and follow it backward toward the initial point. In Fig. 3, " 0 " on the abscissa was defined as the terminal point where b-a learning was completed; and $-1,-2, \ldots,-16$ were defined as the 1 trial, 2 trials, ..., 16 trials before the completion of learning.

It is extremely interesting to note that the experimental curves (Conditions B, C, $\mathrm{D}, \mathrm{E}$, and F) did not differ from each other, excepting in their starting points. This means that among the experimental conditions, no matter where the $S$ started b-a learning, the speed of $b-a$ learning was almost the same at any given stage of $\mathrm{b}-\mathrm{a}$ learning before the terminal point of learning.

However, there was a considerable difference between the control (Condition A) curve and the experimental curves as a whole. This difference required more detailed analysis, which was done in the next section in terms of transfer scores.

Transfer scores
From the data presented in Fig. 2, the scores (number of correct responses) achieved by the experimental groups (Conditions $\mathrm{B}, \mathrm{C}, \mathrm{D}, \mathrm{E}$, and $\mathrm{F}$ ) were converted to the transfer scores, $T_{E}(C)$. A transfer score is defined as the amount, in percentage units, that an experimental $S$ scores beyond that of the average control $S$ performing the same b-a task on the same trial. The scores of each trial of the experimental group were converted to the transfer scores by the following formula:

$$
T_{E}(C)=\frac{E-\bar{C}}{C} \times 100
$$

In this formula, $\mathrm{E}$ represents the number of items of a given b-a list that an $S$ in a given experimental group anticipated correctly on a particular trial. $\bar{C}$ refers to the mean number of items anticipated correctly by the $S$ s of the control group (Condition $A$ ) on the same trial with the same b-a list. $T_{E}(C)$ could be positive or negative, and there were no boundaries to the magnitude of the scores. The formula above is, in essence, identical to the formulas employed by the author previously: Izawa (1962), Izawa et al. (1962), and Horowitz and Izawa (1963).

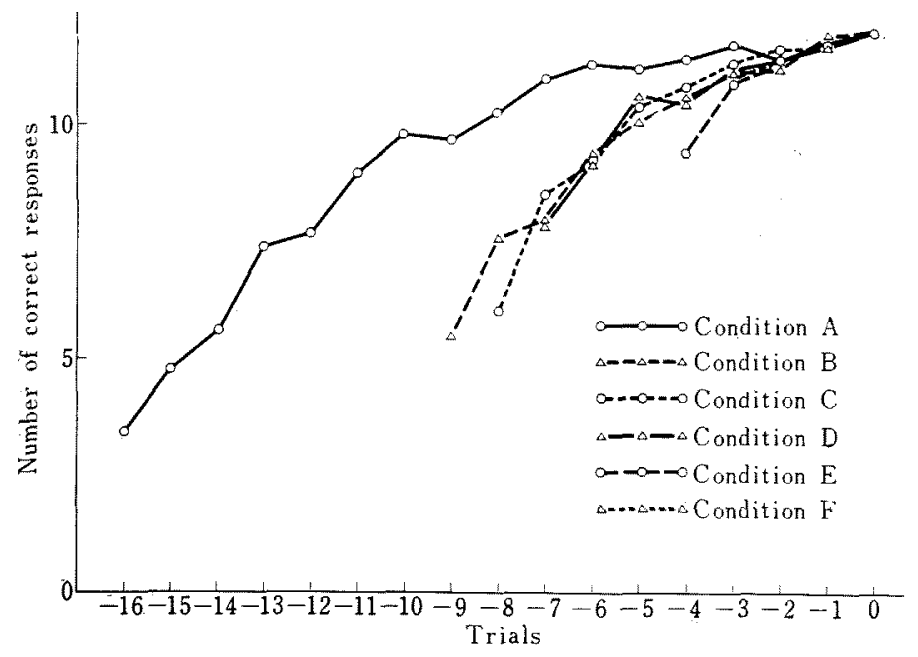

Fig. 3. Backward learning curves. 
TABLE 4

Item analysis

Relationships between forward association formed during $a-b$ learning and backward association produced on TEST

\begin{tabular}{cccccc}
\hline $\begin{array}{c}\text { Forward } \\
\text { association }\end{array}$ & Condition & $\begin{array}{c}\text { Backward association } \\
\text { (Mean number) }\end{array}$ & Total & $\begin{array}{c}\text { Rate } \\
(\%)\end{array}$ \\
\cline { 3 - 5 } & & Produced & Not produced & & \\
\hline \multirow{5}{*}{ Learned } & B & 3.3 & 1.1 & 4.4 & 75.0 \\
& C & 4.2 & 2.9 & 7.1 & 59.2 \\
& D & 6.9 & 3.1 & 10.0 & 69.0 \\
& E & 9.5 & 2.5 & 12.0 & 79.2 \\
& F & 10.9 & 1.1 & 12.0 & 90.8 \\
\hline \multirow{5}{*}{ Not Learned } & B & 2.2 & 5.3 & 7.5 & 28.9 \\
& C & 1.8 & 3.3 & 5.1 & 35.3 \\
& D & 1.0 & 1.0 & 2.0 & 50.0
\end{tabular}

Fig. 4 shows trial by trial records of the mean transfer scores earned by the experimental conditions.

Using the three way classification with 5 cases per cell, an analysis of variance was performed on these data for trials 1 through 4. The obvious reason for the analysis for trials 1 through 4 was that Condition $F$ required only 4 trials to reach the experimental criterion. As might well be expected from Fig. 4, there were highly significant differences between conditions and between trials. The $F$ s for these main effects were $F(4,12)=82.107, p<.001$ and $F(3,12)=105.891 \quad p<.001$ respectively. The interaction between condition and trial was also highly significant: $F(12,12)$ $=8.861, p<.001$. The interaction between trial and list was significant at the .01 level with $F(3,12)=6.874$. No other sources of variation were significant except for a slight difference between lists.

Fig. 4 and the above analysis show that positive transfer occurred from former $a-b$ learning to later $b-a$ learning. The following points are clear: (1) Considerable positive transfer occurred from previous $\mathrm{a}-\mathrm{b}$ learning to later $\mathrm{b}-\mathrm{a}$ learning in terms of both number of trials and number of correct responses. (2) The greater the previous $a-b$ learning, the greater the amount of transfer. (3) For a given ex- perimental condition, the rank order for the transfer scores remained fairly constant. This corresponds to Fig. 2, which shows that the rank order for the probability of correct score remained constant

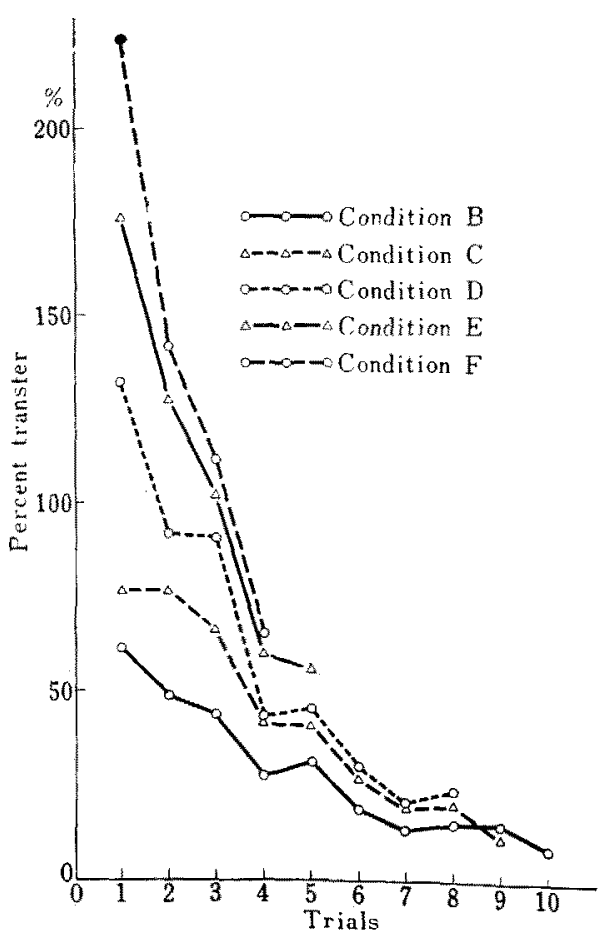

FIG. 4. Transfer curves 
for any experimental condition. Thus, a family of more or less parallel learning curves was generated.

This bit of evidence rules out the possibility that backward association in PAL is a completely different process from forward association. On the contrary, it asserts that forward and backward associations are inseparable, and that they are formed as part of a single or at least a similar process, which is subject to transfer.

\section{Item analysis}

If the availability of items of pairs is the key in explaining the directionality of association, it would be instructive to do an item analysis. In order to understand the relationship between forward association learned during the previous $a-b$ learning and backward association produced on TEST, all pairs were classified into two groups for each of the 5 experimental conditions. One was the "learned" group where forward association of a pair was said to be learned when an assigned criterion was reached. The other was designated the " not learned" group, where no forward association was learned. Then, for each of the groups, all pairs were examined to determine whether they were produced by the backward association TEST. The result of this analysis is shown

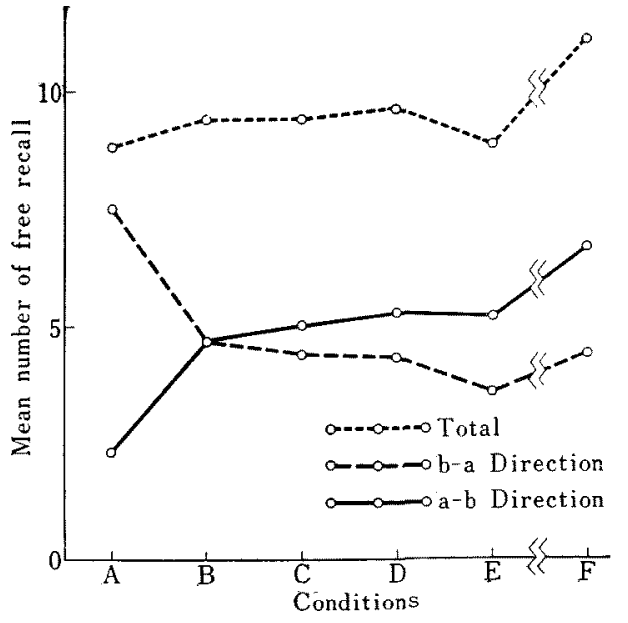

Fig. 5. Mean number of free recall. in Table 4. The last column shows the percentage of backward association of the pairs whose forward association was learned during $a-b$ task, and the percentage of backward association produced from the pairs whose forward association was not learned during the first task.

Table 4 reveals an interesting trend. As the second row of the table indicates, a considerable amount of backward association was produced from the pairs whose forward association was not learned during the first $a-b$ task.

\section{Free association}

The $S \mathrm{~s}$ were asked to recall as many pairs or single items from a pair as possible in any order. None of the $S \mathrm{~s}$, however, produced a single member; the responses always involved a pair. Fig. 5 contains the result of the free recall test.

First, an analysis of variance was performed for each recall direction to test the difference between condition and list. The scores used were the mean total number of recalls for each condition for each list. There was, of course, no difference between lists for both a-b direction, $F(1,5)=2.299$, and b-a direction, $F(\mathrm{I}, 5)=.916$. The differences between conditions, however, were significant: $F(5,5)=12.127, p<.01$, for $a-b$ recall direction; and $F(5,5)=$ $3.542, .05<p<.1$, for b-a recall direction. Secondly, an overall analysis of variance was carried out to test the interaction (recall direction vs. condition). The interaction, as expected from Fig. 4, turned out to be highly significant, $F(5,12)=11.257$, $p<.001$. It is important to note that there was no difference in the total number of free recalls between conditions. That is, the total number of free recalls was rather constant throughout the conditions, but the direction of recalling a pair was systematically different: the more the $a-b$ learning trials, the more free recalls in $\mathrm{a}-\mathrm{b}$ directions, $r=.891 ;^{4}$ and the more $b-a$ learning trials, the more free recall in b-a direction, $r=.854 .{ }^{4}$ The direction of free recall, therefore, was closely correlated with 
the direction of PAL task.

\section{Association test}

The mean number of pairs which were accompanied by the associations created by $S$ himself did not differ throughout the conditions. On the average, $S$ s made up certain associations or mnemonic devices to 6.45 of the 12 pairs $(S . D .=.44)$. Also, the fairly constant number of pairs which were freely recalled had associations, $53.2 \%$ of the time on the average, $S . D .=3.8 \%$. According to the $S \mathrm{~s}$, the pairs which did not have associations or mnemonic devices were "just remembered."

\section{Discussion}

These results suggest that the conclusion drawn by Asch and Ebenholtz needs some modifications. Availability has been defined in terms of free or aided free recall. That is, the item free recalled was an item which was available. If the above statements are correct, then, availability is closely tied with item learning, which is inseparably related to stimulus discrimination learning and response learning of PA tasks. These two kinds of learning along with association learning between a given two items, have to occur during the course of PA acquisition. Then, an available item could be translated as the item which is item-learned.

If availability is defined in terms of free association, and if it is the only key concept which can explain associative symmetry and its cognitive characteristics, then it is inadequate in explaining the results of the free association test of the present study. First, upon taking this free association test, all $S_{\mathrm{s}}$ had an equal amount of b-a learning, since the learning criterion was one perfect production on a single trial for all conditions. The $S$ s did not recall any one independent item, even though they were

4 These correlation coefficients were calculated between the mean trials to criterion of PAI tasks and the mean number of pairs recalled in the freerecall test. told to do so, if they could not remember the other partner of a pair. That is, each $S$ freely recalled exactly the same number of stimulus members as response members. Furthermore, the mean amount of free recall of each of the stimulus and response members was constant throughout the conditions, $M=9.5, S . D .=.737$. The discussion so far seems to support associative symmetry. However, there is one important point which should not be dismissed lightly.

As long as a pair consisted of two members, $S$ had to write down one first, and then the other, connecting them by a hyphen. If association is a fundamentally cognitive process which forms one whole "Gestalt," then there should be no appreciable directionality when the pairs were freely recalled. This follows from the fact that associative symmetry denies the directionality of association, and that the associative process is a unitary cognitive process. The results of the present study (Fig. 5) did not support such an interpretation, since the direction of recall was systematically different depending on the condition. If Table 2 is examined together with Fig. 5, it becomes clear that the more $a-b$ trials of a PA task, the more $\mathrm{a}-\mathrm{b}$ direction occurred: $r=.891$; and the more $\mathrm{b}$-a trials in PAL, the more b-a direction: $r=.854$. Apparently, the direction of recall depended upon the direction of training.

The conclusion arrived at by Asch and Ebenholtz was that the relative weakness of backward association was due to an artifact produced by an experimental operation, namely the anticipation method. Results of Condition B of this study do not support their conclusion. In Condition $\mathrm{B}$, as in all other conditions, a modified anticipation method was employed. Yet, $S$ s in Condition B learned more backward associations than forward associations. Therefore, there is the danger of oversimplification in an explanation which attributes the weakness of backward association entirely to an experimental artifact. 
Stoddard's data (1929), which showed a superiority of backward learning, is not analogous to the results of the present study. In his experiment, the $S$ s of Group $B$ learned 50 pairs with English as the stimulus members and French as the response members, where English was the $S \mathrm{~s}$ ' mother tongue. They were instructed to learn the pairs during $20 \mathrm{~min}$ of learning period. In this condition, backward association (respond in English given a French word) was superior to forward association (respond in French given an English word). His experiment, however, was a test of the function of meaningfulness rather than a test of directionality of association. There is enough evidence in the literature that meaningfulness is a strong factor governing the outcome of such a situation. Functions of meaningfulness have been investigated systematically by such writers as Kuraishi (1937), Morikawa(1955, 1959), Jantz and Underwood(1958), and Hunt (1959). In the present study, however, the factor of meaningfulness did not come in, since both stimulus and response items had the same amount of meaningfulness on the average. The results of this study show that at an early stage of learning of PA task, backward association could be superior to forward association with the anticipation method, if both members of a pair were equally learnable.

An interpretation of backward association was recently proposed by Feldman and Underwood (1957) and Jantz and Underwood (1958). According to these investigators, backward association is an instance of incidental learning. However, the large amounts of backward association obtained under the varied experimental conditions of the present investigation cannot be explained as a product of incidental learning, or of uncontrolled factors.

In summary, the formation of association is still influenced strongly by the direction employed in lcarning. When both items of a pair have the same learnability, the relative weakness of backward association may be due to the directionality of training. The anticipation method did not produce weaker backward associations throughout every stage of PAL. The present study suggests that further investigation of these problems is warranted.

\section{ReFERENCES}

Asch, S. E., \& Ebenholtz, S. M. 1962 The principle of associative symmetry. Proc. Amer. Phil. Soc., 106, 135-163.

Bunch, M. E., \& Lund, W. R. 1932 An experiment on backward association in animal learning. 7. comp. Psychol., 13, 143-156.

Cason, H. 1924 The concept of backward association. Amer. 7. Psychol., 35, 217-221.

CAson, H. 1926 Specific serial learning: A study of backward association. 7. exp. Psychol., 9, 195-227.

Dorcus, M. D. 1932 The establishing of backward association in forward learning of the maze by albino rats. $\mathcal{f}$. comb. Psychol, 13, 11-18.

Feldman, S. M., \& UNDerwood, B. J., 1957 Stimulus recall following paired-associate learning. 7. exp. Psychol., 53, 11-15.

Garretro, \& Hartman. 1926 An experiment on backward association in learning. Amer. 7. Psychol., 37, 241-246.

Grbson, E.J. 1940 A systematic application of the concepts of generalization and differentiation to verbal leaming. Psychol. Rev., 47, 196229.

Guthrie, E. R. 1933 Association as a function of time interval. Psychol. Rev., 40, 355-367.

GUTHRIE, E. R. 1935 The Psychology of Learning. New York: Harper.

Hermans, T. G. 1936 A study of the relative amounts of forward and backward association of verbal material. F. exp. Psychol., 19, 769775.

Horowitz, L. M., Brown, Z. M., \& Weisseluth, S. 1964 Availability and direction of associations. J. exp. Psychol., 68, 541-549,

Horowitz, L. M., \& IzAwa, C. 1963 Comparison of serial aad paired-associate learning. $\mathcal{F}$. exp. Psychol., 65, 352-361.

Hunt, R. G. 1959 Meaningfulness and articulation of stimulus and response in paired associate learning and stimulus recall. F. exp. Psychol., 57, 262-267.

IzAWA, C. 1960 Backward associations in pairedassociate learning. B.A. Thesis Call no. 644 , 
University of Tokyo, Tokyo, Japan.

IzAwa, C. 1962 The relationship between serial learning and paired-associate learning. M.A. Thesis, Stanford University, Stanford, Calif., U.S.A.

Izawa, C., Horowitz, L. M., \& McConkte, G. W. 1962 The stimulus in serial learning. Amer. Psychol., 17, 373.

JANTZ, E. M., \& UNDERWOOD, B.J. 1958 R-S learning as a function of meaningfulness and degree of S-R learning. 7. exp. Psychol., 56, 174-179.

KURAISHI, S. 1937 Recall in simple thinking by the anticipation method. Fap. F. Psychol., 12, 578-602.

Lepley, W. M. 1934 Serial reactions considered as conditioned reactions. Psychol. monogr., 46, no. 205.

McGeoci, J.A., \& IRIon, A. L, 1952 The Pychology of Human Learning. New York: Longmans, Green.

McGeoch, J. A. 1936 The direction and extent of intraserial association at recall. Amer. 7 . Psychol., 48, 221-245.

Meyer, G. 1939 Temporal organization and the initial reproductive tendency. $\mathfrak{\jmath}$. Psychol, , 7, 262-282.

Morikawa, Y. 1955 Studies in paired-associate learning (I). Jap. F. Psychol., 26, 156-171.

Morikawa, Y. 1959 Studies in paired-associate learning (III). Jap. J. Psychol., 30, 153-166. Nagel, F. 1912 Ar. ges. Ps. 23, 156-253.

Peters, H. N. 1935 Mediate association. J.exp. Psychol, 18, 20-48.

Raskin, E., \& Cook, S.W. 1937 The strength and direction of association formed in the learning of nonsense syllables. 7. exp. Psychol., 20, 381-395.

Robinson, E.S. 1932 Association theory today: An essay in systematic psychology. New York: Century.

Stodpard, G. D. 1929 An experiment in verbal learning. 7. $\varepsilon d$. Psychol., 20, 452-457.

Umemoto, T. 1951 The relative weight of stimulus versus response words in rote learning. Jap. J. Psychol., 21, 46-55.

Umemoto, T., Morikawa, Y., \& IBUKr, M. 1955 The non-association values and meaningfulness of 1892 Japanese two-letter syllables and words. Jap. 7. Psychol., 26, 148-155.

Trowbridge, M. H. 1938 A study of backward and remote forward association. 7. exp. Psychol., 22, 319-337.

WiLson, J. T. 1949 The formation and retention of remote association in rote learning. F. exp. Psychol., 39, 830-838.

Wohlgemuth, A. 1912 On memory and the direction of associations. Brit. 7. Psychol, 5, $447-465$.

(Received Feb. 1, 1965) 